\title{
MOBILIDADE MIGRATÓRIA: UMA LEITURA CRÍTICA PARA ALÉM DE METÁFORAS HIDRÁULICAS
}

\author{
Migration Mobility: a critical approach to hydraulic metaphors
}

Resumo. Este artigo explora o conceito de mobilidade migratória. Através de uma revisão crítica da literatura em estudos migratórios, que abordam tal dinâmica social por meio de imprecisas metáforas hidráulicas como, por exemplo, fluxo, fluidez ou onda migratória, demonstro a necessidade do diálogo com outros campos de pesquisa. Estudos fronteiriços e de mobilidade são as duas áreas de pesquisas trabalhadas aqui. Além de travarem íntimo diálogo com os estudos migratórios, oferecem ferramentas conceituais - particularmente, fronteiras inteligentes, espaço social e jornada - capazes de contribuir para o entendimento da migração enquanto uma mobilidade que envolve táticas e é intimamente entrelaçada com fronteiras.

Palavras-chave: mobilidade migratória; jornada; fronteiras; táticas.

Abstract. This article unfolds the concept of migration mobility. Through a critical review of migratory studies which investigate such social dynamic based on hydraulic metaphors such as flow or migration wave, I stress the importance of a dialogue with other study areas. Border and mobile studies are the two fields explored in more details here. In order to engage in a fruitful dialogue with migration studies, I particularly demonstrate how conceptual tools - smart borders, social space, and journey - bring significant contributions to thinking about migration as a tactical mobility intertwined with borders.

Keywords: migration mobility; journey; borders; tactics.

\footnotetext{
Departamento de Ciências Sociais da Universidade Estadual de Montes Claros (Unimontes).
} Montes Claros - MG, Brasil. E-mail: tentonidias@hotmail.com. Orcid: 0000-0001-5325-3253. 
Si la asume de modo acrítico, está aceptando que la inmigración es indeseable y peligrosa, porque una ola es capaz de ahogarte. Y esa idea de ola ya condiciona todo lo que dirás sobre la inmigración.

Teun van Dijk

\section{Introdução}

No documentário In This World (2002), dirigido por Michael Winterbottom, acompanhamos a jornada de Jamal and Enayatullah, dois jovens afegãos, que iniciam a viagem de um campo de refugiados em Peshawar com destino a Londres. Ao longo dessa jornada, os dois rapazes lidam com atravessadores, outros viajantes e, sobretudo, com o forte controle migratório em cada fronteira que cruzam e que, a todo instante, exige com que a rota seja redesenhada, atrasada ou improvisada. Prisão, deportação, exploração e morte os acompanham. Ao final do documentário, uma das mensagens que nos fica é: mobilidade migratória é um movimento que envolve pessoas, habilidades, saberes e, sobretudo, um íntimo diálogo com as fronteiras pelas quais se percorre. Entre a cidade paquistanesa e a capital britânica, existe um longo percurso, um entre-pontos, composto por uma miríade de negociações e resultados e que tende a fugir da análise ou compreensão do expectador. Esse docudrama é um exemplo de incontáveis trilhas secundárias da globalização percorrida por migrantes (Knowles, 2017).

O mundo globalizado contemporâneo, contraditoriamente, caracteriza-se não apenas por maior circularidade de mercadorias, informações e pessoas, mas, sobretudo, por uma multiplicação de fronteiras (Balibar, 2004; Mezzadra, 2015; De Genova, 2004, 2013). Tal proliferação de barreiras, produzida tanto por governos liberais conservadores quanto progressistas, revela um intenso investimento em tecnologia de vigilância. A princípio, o discurso central que sustenta tal política é o da segurança nacional e do ordenamento populacional. Contudo, enviesado por uma leitura aporofóbica, podemos constatar um indiscriminado processo de criminalização, que coloca no mesmo grupo de risco à estabilidade eventuais ataques terroristas e "ondas migratórias" originárias em terras arrasadas (Balibar, 2002; Kubal, 2014). Não surpreendentemente, testemunhamos o crescimento de cercas, patrulhamento e políticas migratórias restritivas que, cada vez mais, têm gerenciado suas fronteiras. A indústria de vigilância é, de fato, um setor crescente. Maguire, Frois e Zurawski (2014) chamam a atenção para o fato de que essa lucrativa indústria é diversificada. Governos, organizações terceirizadas, universidades e indústria bélica participam desse lucrativo mercado. A literatura em estudos fronteiriços revela-nos que a proliferação de tais fronteiras, no mundo contemporâneo, não deixa mais claros os limites do que pode ser entendido como fronteiras exteriores ou fronteiras interiores (Balibar, 2002, 2004; Vila, 
2000; Khosravi, 2010; Mezzadra, 2015; De Genova, 2015). Como apresento nesse artigo, na guerra tecnológica empregada no controle de migrantes, vemos o surgimento de fronteiras inteligentes.

Apesar de uma crescente produção científica explorando as políticas migratórias responsáveis por tais regimes de fronteiras e o impacto desses sobre a vida de migrantes, cabe destacar que, ainda assim, há uma urgente necessidade de mais estudos dedicados à compreensão de como esses atores produzem e negociam sua mobilidade através de tais espaços sociais. A mobilidade migratória, em si, suas táticas de negociação envolvidas ao longo de todas as etapas da jornada - antes, durante e depois - acabam sendo ofuscadas por tradicionais, porém insuficientes, metáforas hidráulicas como, por exemplo, ondas e fluxos migratórios ${ }^{1}$. Sob essa proposta, muitos estudos migratórios - sobretudo, desenvolvidos no Brasil - concentram-se, predominantemente, nos pontos de partida e chegada. Enquanto o trajeto em si e todas as particularidades produzidas pela mobilidade migratória deixam de ser explorados (Oliveira, 2015; Sega, 2018; Assis, 2018).

Com o intuito de suprir tal lacuna, esse artigo argumenta que as zonas de fronteiras devem ser interpretadas enquanto espaços sociais que interagem com migrantes (Dias, 2016, 2018b). Sob essa perspectiva teórica, a mobilidade migratória, em si, não pode ser ignorada ou ocultada. Para isso, torna-se necessário uma profunda compreensão das fronteiras pelas quais ela ocorre e com as quais se conecta, ao longo de sua trajetória. Tal posicionamento crítico possibilita ao/à pesquisador/a compreender a migração não como fluxo, mas como uma prática social do ator migrante carregada de experiências vividas, negociadas e produzidas no espaço. Espaço, portanto, é uma categoria social de extrema importância para estudos de deslocamento humano. É uma das dimensões sociais onde viajantes experienciam, como exemplo, paixões, afetos, deveres, insultos e proibições (Lefebvre, 1991; Tuan, 2013).

Este artigo, assim, contribui para o campo dos estudos migratórios ao refletir, criticamente, através de um enfoque teórico, acerca da produção da mobilidade migratória. Mais do que um movimento entre o ponto A e o ponto $\mathrm{B}$, argumento sobre a necessidade de debatermos como se dá a mobilidade ao longo desse entre-pontos que as metáforas hidráulicas ofuscam e/ou ignoram. Exploro a mobilidade migratória enquanto um processo social constituído

\footnotetext{
É sábido que muitas imprensas nacionais também se utilizam de tais metáforas para divulgar a ideia de que as fronteiras nacionais estão sendo "inundadas" por estrangeiros. Como exemplo, cito os programas britânico UK Border Forcer, irlandês Customs, estadunidense Homeland Security USA, australiano Border Security: Australia's Front Line e o canadense Border Security: Canada's Front Line. Ressalto, ainda, que, nesses programas, migração ou refúgio recebem um tratamento criminal, já que migrantes e refugiados são retratados juntamente com traficantes e terroristas. Contudo, a preocupação central, nesse artigo, é com a presença das metáforas hidráulicas na literatura produzida pelos estudos migratórios.
} 
por habilidades e constante negociação com fronteiras. Deixo claro que não objetivo romantizá-la e nem ignorar o drama vivido por esses sujeitos, seja na travessia pelas fronteiras da Venezuela-Brasil, através dos muros na fronteira México-EUA, ou dos corpos não brancos diariamente afogados no Mediterrâneo. À luz disto, o quadro conceitual para este texto abrange estudos de fronteiras e, principalmente, de mobilidade. A abordagem teórica adotada aqui permitirá fornecer contribuições conceituais sobre processos que têm sido documentados, com frequência, por estudos de migração e até mesmo de fronteira, como demonstrarei, mas de maneira insuficiente. O primeiro passo, portanto, é compreender como as metáforas hidráulicas colonizaram os estudos migratórios²

\section{Metáforas hidráulicas}

Na década de 1990, o discurso da globalização e do cosmopolitismo, inclusive no cenário acadêmico, passaram a dar um forte destaque à circulação global de pessoas, objetos e ideias (Schrooten, Salazar, Dias, 2015). John Urry (2000) define esse período como a Idade de Ouro da Globalização. Segundo o autor, foi um fenômeno que marcou uma alta densidade de interações globais através de inovações tecnológicas e sociais, que reorganizaram e comprimiram, drasticamente, as próprias dimensões do tempo e do espaço entre pessoas e lugares. De acordo com ele, promoveu a circulação de diversos tipos de pessoas móveis, incluindo migrantes, resultando no que ele chama de uma "aldeia global" (Urry, 2007). A globalização foi promovida como a normalidade, na medida em que as metáforas hidráulicas como, por exemplo, "fluxos", "fluidez" e "ondas" quase chegaram a monopolizar a discussão das novas formas de mobilidade global (Rockefeller, 2011; Salazar, 2013)³.

Inspirados por conceitos teóricos que exploram "a compressão do tempoespaço" (Harvey, 1989), estudos migratórios passaram, assim, a trabalhar com a ideia de que as mudanças estruturais na economia global produziram uma nova dinâmica móvel no mundo. As distâncias espaço-temporais haviam sido

2 Destaco que, por motivos de limite de palavras e do próprio artigo, eu não pretendo abordar todo o debate em torno do tema que é amplo e está em constante avanço. Trago aqui, todavia, exemplos que dialogam diretamente com a minha proposta.

3 Cabe destacar que essa leitura crítica aos estudos migratórios que se valem de metáforas hidráulicas para explicar a mobilidade transnacional, não é recente. Um retrospecto cuidadoso nos leva aos críticos textos redigidos por Abdelmalek Sayad nas décadas de 1970 e 1980. Sob forte influência de seu estudo pioneiro, em parceria com Pierre Bourdieu, Le déracinement: La crise de l'agriculture traditionnelle en Algérie (1964), Sayad viria, posteriormente, a desenvolver uma forte crítica aos estudos migratórios franceses pautados na leitura neoclássica do push-pull. Como Gennaro Avallone e Enríque Santamaría cuidadosamente expõem (2018), tal modelo, articulado pelo conjunto de fatores macroeconomicos de expulsão e atração, buscava explicar, de forma generalista, os fluxos migratórios internacionais. Sayad, assim, denunciava como essa leitura ortodoxa reduzia complexos movimentos, com particularidades históricas e subjetivas, a uma natureza osmótica. 
dramaticamente condensadas através do aperfeiçoamento das tecnologias de comunicação e transporte, possibilitando uma maior circulação de trabalhadores. Essa foi a tônica que permeou, por exemplo, os estudos da "primeira onda migratória brasileira", no período referido.

A emigração de brasileiros para outros países do mundo é parte de um processo de mobilidade espacial que vem se acentuando ao longo da última década e pelo qual os países industrializados passaram a receber milhares de trabalhadores, sobretudo jovens, que deixaram seus países de origem em busca de novas oportunidades de trabalho e melhores condições de vida. (Bógus, 1995, p. 16)

A migração transnacional passou a ser compreendida enquanto uma característica do mundo globalizado moderno (Appadurai, 1996; Castles, Miller, 2009). Contudo, apesar da visível multiplicação de fronteiras, nas últimas décadas, como será explorado na próxima seção, é possível constatar que os estudos migratórios contemporâneos mantiveram essa leitura. Em geral, desenvolveram uma crítica insuficiente em relação à suposta "fluidez" na circulação transfronteiriça, bem como pouco exploram o impacto dessas fronteiras ao longo da mobilidade produzida por migrantes. Estudos transnacionais, por exemplo, reconhecem a circulação fronteiriça de pessoas, bens e informações, mas, em geral, pouco esmiúçam como esses movimentos são negociados e produzidos com os ditos regimes de fronteiras. A mobilidade, em si, é deturpada por uma ampla definição de redes informais que permitem tal fluxo trasnacional (Sheringham, 2009; Ferreira, 2018). Para esses pesquisadores, tais redes fornecem recursos vitais para indivíduos e grupos, e podem ser vistas como capital social, que inclui relacionamentos pessoais, padrões familiares e domésticos, laços de amizade, comunidade e ajuda mútua em questões econômicas e sociais (Castles, Miller, 2009). As redes informais, de acordo com esses estudos, têm a capacidade de unir "migrantes e não migrantes em uma complexa malha de papéis sociais e relações interpessoais" (Boyd, 1989, p. 639). Como resultado, elas permitem migrantes fluírem abstratamente entre os territórios. Todavia, a relação tensa estabelecida entre o sujeito migrante e as fronteiras pelas quais ele passa para alcançar esse movimento transnacional segue insuficientemente explorada.

Dessa forma, mesmo que tais redes informais tenham uma forte indústria migratória por trás de si, como veremos adiante, capaz de prover conexões para que a circulação transfronteiriça ocorra em larga escala, a negociação com fronteiras ainda se encontra presente e não pode ser ignorada. As imagens do pequeno sírio Aylan Kurdi, já sem vida, desoladamente jogado em alguma praia turca, após uma fracassada travessia pelo Mediterrâneo, em 2015, ou do salvadorenho Óscar Martínez Ramírez e sua filha, Valéria, afogados ao tentar atravessar a fronteira México-EUA pelo Rio Grande, nesse ano, são dois entre 
milhares de exemplos de tragédias vividas por migrantes que, diariamente, arriscam suas mobilidades nada fluidas através das fronteiras para alcançar, por exemplo, o Norte Global.

Esses estudos, portanto, acabam não tendo o cuidado de desdobrar os distintos tipos de mobilidades e como cada uma negocia sua existência com severos regimes de fronteiras. Mobilidade migratória, de forma pouco cuidadosa, é tratada de forma simétrica com outras formas de mobilidades como, por exemplo, de turistas ou estudantes internacionais. Enquanto pesquisadores comprometidos em apontar as contradições que permeiam esse suposto mundo global em movimento, precisamos desdobrá-la com maior acuidade com o objetivo de compreender como migrantes negociam sua mobilidade e o quanto ela é assimétrica em relação às demais.

Assim, propostas investigativas, assentadas em metáforas hidráulicas, apresentam-se inadequadas para a compreensão dos processos de mobilidade contemporânea. Embora o campo dos estudos migratórios seja um campo de pesquisa intimamente associado ao movimento humano, não exploramos suficientemente as formas mais variadas de mobilidade produzida por esses sujeitos (Khosravi, 2010; Papadopoulos, Stephenson, Tsianos, 2008). Pesquisas tendem a focar excessivamente no início e nos supostos pontos finais da jornada migratória, prestando especial atenção ao processo de tomada de decisões antes da partida, por um lado, e integração nos países de destino e à manutenção de contactos transnacionais por outro. Contudo, a condição vivida nas fronteiras, seja por escolha ou por necessidade, que tipifica a vida de muitos desses sujeitos, não é, no entanto, capturada pelos conceitos atualmente empregados nos estudos migratórios. Creio que aqui os estudos fronteiriços e de mobilidade oferem significativas contribuições para os estudos migratórios.

\section{Fronteiras inteligentes e tipos de mobilidade}

Baseado em uma perspectiva que nos possibilite posicionar o migrante enquanto um ator social -com o objetivo de superar uma leitura excessivamente macro -, argumento que a mobilidade migratória é uma prática social que envolve uma íntima interação entre sujeito e o espaço pelo qual circula. Como Fulvio Rivero Sierra argumenta, espaço não deve ser compreendido apenas por meio de suas qualidades naturais, físicas e econômicas, mas como o resultado de uma relação inextricável, "entre el sujeto migrante y ese espacio, por la cual lo incorpora a su subjetividad mediante mecanismos complejos que lo transforman, lo redefinen, lo apropian y lo re significan para sí" (2018, p. 46). Nesta direção, é possível pensar tal perspectiva através da definição de espaço social cunhada por Henri Lefevbre (1991), que desenvolveu, a partir do conceito marxista de "produção", a construção de uma teoria unitária 
de distintos espaços - físico, mental e social -, onde o espaço é concebido como um "produto social" resultante de um conjunto de relações. Combinada com a ideia de espaço vivido, desenvolvida, também, por Lefebvre, na obra The production of Space, tal definição de espaço social permite-nos uma compreensão mais refinada sobre como os migrantes lidam com os controles de fronteira. E é essa a proposta desse artigo: a possibilidade de compreender fronteiras a partir de uma perspectiva fundamentada na sua própria produção. Afinal, considero que o conceito de mobilidade migratória é resultado indissociavel do conceito de fronteira (Benedetti, 2014).

Fronteiras são parte dimensional da mobilidade migratória. Como resultado, dão sentido aos itinerários que conectam a mobilidade ao sujeito migrante. Os estudos de Dimitris Papadopolous, Niamh Stephenson e Vassilis Tsianos (2008), bem como de Sandro Mezzadra e Brett Neilson (2013), observam com singular precisão que, embora a mobilidade humana tenha aumentado, graças a uma economia global ávida por força laboral, governos nacionais têm, gradualmente, reforçado o controle de suas fronteiras, bem como aumentado a restrição da livre circulação humana por entre territórios. Segundo esses autores, em um mundo globalizado, essas restrições operadas em zonas de fronteiras, contraditoriamente, têm desempenhado um papel crucial na circulação de pessoas, visto que geram um sentimento de exclusão na medida em que regulamentam tal mobilidade.

Longe de barreiras geográficas que servem apenas para bloquear ou obstruir a passagem global de pessoas, as fronteiras contemporâneas tornaram-se flexíveis e estão em constante formação (Mezzadra, Neilson, 2013; ver também Perera, 2009). Nesse sentido, estudos atuais argumentam que, hoje, as fronteiras não podem ser entendidas como coisas. São relações produzidas por reforços de fronteira e movimentos de passagem de fronteira (Balibar, 2002; Vila, 2000). Ademais, são espaços sociais de controle que, no início desse século, tiveram como tônica um discurso centrado no bloqueio da entrada de possíveis terroristas; logo, incluíram, em seu espectro vigilante, outros tipos de viajantes indesejados como, por exemplo, migrantes e refugiados (Jardim, 2016).

Em geral, a literatura sobre fronteiras, desde os atentados cometidos nos Estados Unidos (2001), Espanha (2004) e Inglaterra (2005), tem evidenciado o crescente regime de fronteiras. Estudos desenvolvidos no Norte Global demonstram a lucrativa indústria de vigilância desenvolvida com tecnologia bélica capaz de distinguir tipos de viajantes e remover qualquer um que ameace a estabilidade do Estado nacional (Curry, 2004; Côté-Boucher, 2008; Maguire, Frois, Zurawski, 2014). Como apresentado na introdução desse artigo, governos, juntamente com universidades, a indústria bélica, e até organizações terceirizadas, atuam diretamente nesse lucrativo mercado 
global $^{4}$. Todavia, cabe destacar que tal cenário de controle não é exclusivo do Norte Global.

A América Latina passa por um um cenário parecido, mesmo durante o ciclo de governos progressistas que ocorreu no início dos anos 2000 (Albuquerque, 2015; Domenech, 2015, 2017; Jardim, 2016; Solís, Aguilar, 2015)5. Como Eduardo Domenech bem destaca, apesar de uma crença inquestionável de que "en la región sudamericana las políticas migratorias habrían superado el 'paradigma' o 'enfoque' de la seguridad y el control en favor de uno basado en los derechos humanos" (2017, p. 21), o processo da securitização da migração seguiu bastante presente no cenário político regional. Na mesma linha argumentativa, Clara Dalmasso (2016) explora como tal processo produz o que ela define enquanto um quadro de (in)securitização vivido por migrantes na Argentina. Segundo a pesquisadora, o desenvolvimento de tecnologias de controle visa criar perfis de suspeitos, gerar trocas de informações e estratégias entre países não só na América Latina, mas entre esses e países no Norte Global legitimados por um discurso de segurança. Esse enfoque é, também, trabalhado por Daniel Villafuerte Solís e María del Carmen García Aguilar (2015), ao abordarem o sistema migratório na América Central e o regime de fronteiras no Sul do México. Eles demonstram como essa região, durante o governo de Felipe Calderón (2006-2012), tornou-se um centro nevrálgico, cujas políticas de segurança nacional foram diretamente desenvolvidas através de colaboração com o governo dos Estados Unidos.

En el sur se incrementó el control de los llamados pasos ciegos y oficiales a lo largo de la línea fronteriza, también se creó el Centro de Administración Integral al Tránsito Fronterizo en el municipio de Playas de Catazajá, que fungirá como un centro de control en la zona norte de Chiapas, importante corredor migratorio de centroamericanos a Estados Unidos. También destaca la presencia de elementos de la gendarmería nacional, policía federal recién creada. (Solís, Aguilar, 2015, p. 84)

Por meio de um amplo aparato tecnológico - cartões biométricos de identificação, passaportes eletrônicos ${ }^{6}$ e e-Gates -, reforçado por agentes

4 Maiores informações podem ser acessadas na página do projeto The Migrants Files (https://www. themigrantsfiles.com/). Trata-se de um projeto conduzido por jornalistas europeus e que visa avaliar com precisão o número de homens, mulheres e crianças que morreram como resultado das políticas de migração da UE.

5 Apesar de ser um fluxo relativamente menos evidenciado, a mobilidade migratória entre países periféricos cresce de forma progressiva. "Como resultado desta tendência, segundo o Banco Mundial, 84,3 milhões de pessoas - isto é, 34\% dos fluxos internacionais - se deslocaram na direção Sul-Norte em 2015, enquanto que 93,1 milhões de pessoas (equivalentes a 38\% da migração global) o fizeram entre países em desenvolvimento" (Villamar, Almeida, 2017, p. 11). Na mesma proporção, os postos de controles fronteiriços também se expandem entre os estados (Baeninger, 2018).

6 Tais documentos são capazes de armazenar informações biométricas do portador (fotografia facial e dados de impressões digitais e de íris digitalizadas), o que permite cruzar informações entre agentes migratórios situados em fronteiras geográficas e/ou em territórios internos, em escala mundial. 
treinados, os controles de fronteiras migratórias procuram identificar perfis, filtrá-los e selecioná-los com precisão. Ademais, trocam informações entre distintos postos migratórios e agentes de fronteiras que circulam por dentro do território. Vemos, portanto, nesse mundo global, a presença das ditas fronteiras inteligentes, novos sistemas de gerenciamento de fronteiras capazes de controlar a entrada e saída de cidadãos, bem como armazenar seus dados biométricos para que possam ser acessados território adentro e compartilhados com outros governos.

Fronteiras inteligentes são posicionadas ao longo das rotas, construindo um aparato que pode seguir indivíduos sobre múltiplas linhas de deslocamento e verificar suas identidades em vários locais nessas linhas. Como Denise Jardim (2016) destaca, há uma "variação" e "capilarização" de tecnologias de controle capazes de conectar diversas dimensões nacionais e internacionais de controles fronteiriços responsáveis por classificar identidades. Segundo a autora, tratam-se de "[t]ecnologias que identificam e, ao mesmo tempo, potencializam e/ou restringem a circulação internacional. Afinal, não basta ter acesso a um passaporte. É preciso que acordos internacionais repercutam no modo como são recepcionados em outro Estado nacional" (2016, p. 250). Elas funcionam, igualmente, como "dispositivos de inclusão que selecionam e filtram pessoas e diferentes formas de circulação de formas não menos violentas do que aquelas implantadas em medidas excludentes" (Mezzadra, Neilson, 2013, p. 7). Tendo isso em conta, a fronteira abrange um "variegated spectrum of spaces, and inevitably also includes the airports (or seaports) where migrants undergo inspection by immigration authorities commonly as documented migrants or travellers first, with visas that later may be overstayed or violated" (De Genova, 2013, p. 4).

Quanto mais a circulação de pessoas ocorre em distintas escalas, em todo o mundo, mais regimes de fronteiras se entrelaçam nas fronteiras geográficas e no território interno. Distintas malhas de mobilidade paradoxalmente produzem malhas de vigilância. Todavia, como a literatura bem destaca, é importante observar que esse enrijecimento político não atinge de maneira comum e cabível todo e qualquer tipo de viajante que se empenhe em cruzar alguma fronteira territorial; o tratamento dispensado nas zonas de fronteira, na realidade, difere-se de acordo com o perfil do viajante.

Dessa forma, exploro a perspectiva conceitual de que fronteiras são marcadas por uso. Dependendo do viajante e de seu status político-econômico, o tratamento oferecido pelo controle de fronteiras é distinto. Nesta direção, fronteiras não devem ser compreendidas de forma desconectada de quem as atravessam, mas como espaços sociais que também produzem um senso de exclusão e desconexão, segundo o perfil do viajante. 
Turistas, por um lado, são vistos como pessoas móveis desejáveis, pois são viajantes temporários que visitam locais e, enquanto consumidores, promovem a circulação de dinheiro e bens materiais e, por assim ser, geram benefícios econômicos para o local visitado (Urry, 2000, 2007). Karine Côté-Boucher (2008) e Michael Curry (2004) destacam que esse perfil econômico é positivamente classificado por agentes migratórios localizados em controles de fronteiras. Classificação similar é concedida a empresários e estudantes internacionais, cuja mobilidade temporária é parte de um almejado e inquestionável estilo de vida, no mundo global.

Migrantes, por outro lado, estariam engendrados na categoria de grupo de risco e, portanto, são considerados indesejáveis (Cresswell, 2006; Papadopoulos, Stephenson, Tsianos, 2008). Em geral, a mobilidade migratória é retratada como um movimento transgressivo, pois o tempo de estadia, as condições econômicas dos migrantes e suas motivações para entrar no território são questões que criam incertezas e inseguranças territoriais ${ }^{7}$. Dessa forma, governos nacionais assumem a responsabilidade de controlar o movimento desses viajantes, reiterando um discurso que se foca, evidentemente, na preservação das integridades cultural e econômica do Estado-Nação (Balibar, 2002; Perera, 2009). Tal discurso reforça-se, sobretudo, em períodos econômicos incertos, nos quais governos nacionalistas e de extrema-direita ganham força ao propagar ideais patrióticos voltados para o combate de possíveis riscos externos. Controles de passaporte, checkpoints e até embaixadas seriam alguns dos espaços sociais com os quais migrantes têm que lidar, constantemente, ao longo de sua mobilidade. São espaços que podem operar através da geração de medo, insegurança e exclusão.

\footnotetext{
É claro que esta forma de rotular os migrantes pelas autoridades não é recente. Tim Cresswell (2006) e Papadopoulos, Stephenson e Tsianos (2008) observam que a definição de migração remonta ao termo vagabundagem, iniciado no final da Idade Média. Desde então, tem se tornado cada vez mais amplo. Creswell, por exemplo, argumenta que esse tipo de sujeito móvel sempre existiu nas margens do estado. Isso está ligado à ideia de povos nômades, historicamente associados a imagens dos sem-teto, errantes, nômades, ciganos e não-assalariados, que poderiam colocar em risco a segurança de um lugar e sua cultura enraizada "intransigence and obdurate rebelliousness" (2006, p. 45). Como resultado, isso "created the need for a new societal-level state ordering system. The vagabond was scary because of his apparent freedom to move and escape the status of adscritpus glebae, as well as the mutual gaze that ensured premodern orders. This new movement was seen as unpredictable" (2006, p. 12). Na mesma linha, Papadopolous, Stephenson e Tsianos ressaltam que "in vagabondage we see a paradigmatic image of the constant drift out of biological discipline, a drift which simultaneously forced the development of some of the core strategies for the control of migration which we encounter today" (2008, p. 41). Os viajantes desenraizados foram vistos como pessoas móveis desamparadas e descontroladas. Portanto, era supostamente o papel do Estado impor controle sobre eles. De acordo com esses estudiosos, tal estigma, historicamente associado a vagabundos e outros tipos de pessoas móveis marginalizadas, também incluiu os atuais migrantes do Sul Global, que pretendem cruzar as fronteiras das cidades ricas localizadas no Norte Global.
} 
De fato, a definição de fobia em relação ao espaço, explorada, inicialmente, por Gaston Bachelard (2000) e, em seguida, por Yi-Fu Tuan (2013), ganha grande relevância para interpretarmos o atual cenário migratório [...]. Espaços sociais que compõem, por exemplo, o tecido urbano de cidades como Londres, e que são ordinariamente frequentados por citadinos, tornamse hostis e seletivos. Ao contrário de uma cidade atrativa e produtora de intimidade, capaz de gerar uma sensação de bem-estar a esses migrantes, o que temos é, através de rigorosas políticas migratórias, a produção de topofobia. (Dias, 2018a, p. 128, grifo meu)

Podemos observar, assim, que o diálogo entre migrantes e controles de fronteiras migratórias retrata uma mobilidade bastante peculiar e distinta da experenciada por turistas, estudantes e empresários.

\section{Migração enquanto uma mobilidade através de fronteiras}

Para compreender as peculiaridades presentes na mobilidade migratória, torna-se necessário um conceito menos abstrato, mais empiricamente engajado, e capaz de expor suas práticas e texturas sociais. Em outras palavras, um conceito capaz de oferecer a chance de aprofundar a análise da mobilidade. E as tais metáforas hidráulicas estão longe de satisfazer tal necessidade. Para tal, sugiro recorrer aos estudos de mobilidade, ainda pouco conhecidos no Brasil. Uma gama de estudiosos tem prestado atenção às práticas de mobilidade como experimentadas pelos sujeitos (Ingold, 2000, 2011a, 2011b; De Certeau 1997; Knowles, 2011; Knowles, 2017; Dias, 2018b; Rivero Sierra, 2018). Como dito anteriormente, enquanto nos estudos migratórios, em geral, o interesse real parece não estar no movimento, mas, sim, na partida e/ou chegada (envolvendo questões de desenraizamento e integração), "mobilidade" tornou-se uma palavra-chave nas ciências sociais, delineando um novo domínio de debates, abordagens e metodologias que buscam compreender os processos contemporâneos de movimento. Embora a mobilidade em si não seja uma ideia nova nas ciências sociais, a ideia de um paradigma de mobilidades ganhou um impulso considerável na última década (Cresswell, 2006; Salazar, 2013).

O conceito de jornada, em particular, fornece-nos uma maneira eficaz de pensar sobre como os viajantes envolvem-se com lugares em itinerários durante todo o processo de migração. Por meio dessa ferramenta conceitual, podemos escapar de uma leitura macro e compreender como o conflitivo diálogo entre migração e fronteiras se desdobra na prática. Trata-se de um movimento baseado não exclusivamente na arquitetura espacial ou rotas convencionais/comerciais que permitem um certo "fluxo", mas, também, em um mapa mental capaz de guiar o viajante em espaços através de um itinerário que faz sentido e, sobretudo, assegura conexão ao longo dos entre-pontos. "As jornadas, em outras palavras, desenham os mapas das pessoas, assim como os 
lugares pelos quais elas passam, fornecendo, portanto, uma maneira de pensar sobre elas a qual incorpora o espaço e o movimento" (Knowles, 2017, p. 27).

Fronteira, apesar de ser um espaço geometricamente racionalizado por forças reguladoras, pode ser utilizado, ressignificado e atualizado por aqueles que o percorrem (De Certeau, 1997). Por meio da mobilidade, migrantes reapropriam, subjetivamente, tal espaço sem, todavia, destituir o seu domínio cartográfico. Podemos dizer que se, por um lado, a fronteira busca imobilizar o ir e vir de migrantes, por outro lado, ela possibilita com que esses sujeitos incorporem as particularidades do espaço e desenvolvam habilidades para superá-lo. Tal diálogo tenso tem, portanto, o migrante enquanto um ator capaz de transformar o próprio regime de fronteiras. Em outras palavras, mobilidade migratória seria uma microrresistência criativa que permite ao migrante fugir da disciplina racional e das proibições que imperam no espaço de fronteira ao mesmo tempo que o força a se reconfigurar (Papadopolous, Stephenson, Tsianos, 2018).

Essa invenção dá-se graças ao que defino como táticas de mobilidade migratória, ou seja, movimentos astuciosos capazes de estabelecer, temporariamente, uma reapropriação das vias de circulação, segundo a particularidade de cada fronteira e, consequentemente, alterar sutilmente lógicas e códigos instituídos nesses espaços. Tática traz a ideia de autonomia, capacidade de negociação e superação por parte de migrantes que passam a ser compreendidos enquanto atores, também, empoderados. Seguindo uma cartografia particular, táticas de mobilidade fronteiriça produzem o que Suvendrini Perera define como uma astuta geography of action (2009). Elas enunciam itinerários pouco claros que são produzidos, entre os supostos pontos de partida e chegada, e que não necessariamente obedecem aos contornos cartográficos oficiais presentes em mapas. De outro modo, elas atendem dinâmicas particulares e momentâneas segundo a necessidade do viajante, as quais dificilmente são repetidas com precisão. Assim, podemos afirmar que as táticas de mobilidade migratória não seguem e nem estabelecem padrões, o que confunde a racionalidade por detrás de um mapa padronizado e, consequentemente, passível de monitoramento. Elas seriam formas de reutilizar o espaço monitorado por controles migratórios, que não permitem uma mobilidade exposta daqueles que são considerados viajantes indesejados. Tais táticas possibilitam, a pesquisadores, imaginar novas cartografias em espaços estrategicamente monitorados por sistemas de vigilância (De Certeau, 1997; Garelli, 2012).

Como dito no início, sem a proposta de romantizar tal mobilidade e, assim, correr o risco de ofuscarmos tragédias envolvidas nessas jornadas, reforço que migrantes empregam táticas perspicazes para reinventar sua jornada na negociação com instituições e estruturas de poder, as quais gerenciam e 
delimitam seu movimento com alvos e ameaças. Migrar é uma mobilidade que envolve habilidade e conhecimento. Todavia, cabe fazer-nos a seguinte pergunta: O que seria, então, essa habilidade?

Inspirado no trabalho de Caroline Knowles e Douglas Harper acerca da mobilidade produzida por migrantes em Hong Kong, entendo habilidade enquanto um conhecimento sobre o mundo e como atuar nele próprio. "It is not confined to employment. Skill is generally demonstrated in the practical operation of routine activities in everyday life" (2009, p. 232). Mobilidade, através das fronteiras, deve ser entendida enquanto manobra qualificada que envolve conhecimentos práticos e troca de experiências de vida sobre o mundo globalizado que esses sujeitos migrantes experienciam e vivem. Não há fluxo, mas negociação.

Com o objetivo de evitar uma viagem sob constante vigilância, migrantes procuram produzir jornadas menos conhecidas e, supostamente, menos controladas por autoridades fronteiriças. Portanto, supostamente mais fáceis para negociar a travessia. Retomando a definição conceitual de Perera, geography of action, a mobilidade migratória não envolve um movimento retilíneo da sociedade emigratória para a imigratória, mas um movimento através de aparentes espaços desconectados, que pode demandar pausas, exigir percursos mais longos e uma constante reflexão sobre a rota a qual se percorre, sempre com o notado interesse de superar os controles de fronteira e buscar possíveis porosidades fronteiriças. Dessa forma, mobilidade migratória não necessariamente tem sua eficiência atestada pela velocidade no deslocamento, mas na certeza de que ele ocorra. Curiosamente, migrantes mostram-nos que, nesse mundo global, marcado pela "compressão do tempoespaço" (Harvey, 1989), eficácia não necessariamente significa velocidade. Trata-se, sim, de segurança e completude. Como apresentado anteriormente, qualquer falha pode significar, em muitos casos, morte.

Para tal, ao longo da mobilidade migratória, diversos sujeitos desempenham papéis significativos na jornada daqueles que migram. Em geral, são pessoas com destreza e conhecimento suficiente sobre o espaço social a ser navegado. Como Papadopoulos, Stephenson e Tsianos salientam, graças a essa habilidade de esgueirarem-se e até negociarem com oficiais de fronteiras, tais agentes recebem denominações zoomorfas - coiotes, cabeça de cobra, corvos ou tubarões ${ }^{8}$ - uma vez que, dependendo do espaço pelo qual navegam, são capazes de ressignificarem sua mobilidade e, então, superar vigilâncias

8 "Coiotes" são pessoas especializadas na mobilidade migratória por entre as fronteiras mexicana e estadunidense; "cabeça de cobra" são pessoas especializadas no tráfego de chineses para fora da China; "tubarões", por sua vez, são donos de embarcações que realizam a travessia marítima pelo Mediterrâneo; e, por fim, "corvos" são pessoas especializadas na travessia através dos Balcãs, com destino à Europa Ocidental. 
fronteiriças. Em outras palavras, a mobilidade migratória revela-se enquanto uma mobilidade produzida por "especialistas" em controlar as adversidades produzidas no/pelo espaço (Rivero Sierra, 2018). Migrantes, portanto, tendem a chegar no novo país através de locais periféricos. Popularmente conhecidas como bordas, essas regiões são caracterizadas por serem pouco habitadas e de difícil patrulhamento; a saber, pequenas ilhas costeiras, cinturões desérticos, áreas montanhosas, enclaves territoriais ou vilarejos.

\section{Conclusão}

Esse artigo contribui para o dossiê através de um profícuo debate em torno da mobilidade produzida por migrantes. Como a literatura tradicionalmente explora, migrantes, de fato, movem-se através de redes de contatos que os antecedem e nas quais também contribuem para sua expansão. "Pero no sólo echa mano de una red contactos, sino que esos contactos, más o menos cercanos, están ubicados en un mapa entramado de 'lugares' que se conectan entre sí" (Rivero Sierra, 2018, p. 40). Todas as formas de mobilidade são executadas através de um íntimo diálogo com o espaço, no contexto de suas próprias circunstâncias e seus desafios. Migração não é diferente.

Pessoas em movimento, talvez, uma das grandes promoções desse mundo global, têm biografias, desenvolvem trajetórias, travam relações com os espaços sociais pelos quais percorrem e conectam suas jornadas. Nesse contexto, a mobilidade migratória, ponto de reflexão nesse artigo, deve ser entendida enquanto um movimento composto por inúmeras práticas sociais. Um migrante é um praticante experiente que participa dos espaços por onde passa. Nas palavras de Knowles, não fluem de um local para outro, eles "bump awkwardly along creating pathways as they go; they grate against each other; they dodge, stop and go, negotiate obstacles, back-track and move off in new directions propelled by different intersecting logics" (2011, p. 174). A migração é, portanto, interpretada, neste artigo, como uma negociação embutida em ações - representadas, principalmente, por conhecimentos e habilidades para agenciar, com os controles de fronteiras, uma mobilidade.

Por meio de um cuidadoso diálogo entre o campo dos estudos migratórios com os estudos de fronteiras e de mobilidade, esse artigo oferece contribuição para pesquisas dedicadas à compreensão da mobilidade migratória. Através deste corpo de literatura, eu argumento que a migração precisa ser entendida através das negociações, conectando pessoas e lugares, ao invés de vê-la como apenas a ida de A para B. O entre-pontos que conecta a saída (A) e a suposta chegada (B), apesar de aparentemente destituído de importância e, portanto, ignorado, é significativo e carregado de poder. Portanto, os lugares estão conectados nas rotas não como arenas de enraizamento fixo, mas como espaços flexíveis que também foram transformados e moldados através 
da mobilidade migratória. Como argumento no desenvolvimento do texto, migrações transnacionais não são um movimento fluídico ou, muitas vezes, linear, como parte considerável da literatura descuidadosamente aponta. Em um mundo globalizado, onde regimes fronteiriços multiplicam-se, precisamos ter o comprometimento de demonstrar como controles de fronteiras fazem parte da mobilidade migratória. Os espaços sociais presentes no entre-pontos, a todo instante, denunciam e expõem o sujeito migrante perante a uma lei que o criminaliza.

Migrar é uma mobilidade tática produzida através de um conjunto de relações sociais em um ambiente onde distintas dimensões interagem em diferentes níveis de conexões. Migrantes, portanto, estão conectados a uma malha social, registrando sua biografia ao longo das rotas que ligam os espaços sociais envolvidos em sua mobilidade. Tal abordagem possibilita-nos refletir como a mobilidade migratória não é superficial ou fluida, mas truncada, qualificada e profunda. Ela afeta e transforma vidas e os espaços por onde ocorre, bem como conecta os próprios sujeitos migrantes aos lugares enquanto nós em uma matriz de movimentos (Ingold, 2000). As diversas mobilidades que compõem o mundo social são diversas e emaranhadas. Migrantes têm suas próprias trajetórias, geografias e conexões; e eles movem-se em velocidades diferentes e através de lógicas bem diferentes. Desagregar e explorar essas mobilidades - em vez de agregá-las e abstraí-las - é o caminho para uma compreensão ética. Em outras palavras, tal perspectiva teórica possibilita com que migrantes ganhem o devido protagonismo, bem como as barbáries produzidas nesses espaços sejam evidenciadas. Logo, migrantes e sua forma de mover já não devem ser mais obscurecidos por imprecisas metáforas hidráulicas.

\section{Referências bibliográficas}

ALBUQUERQUE, Lindomar. Migração, circulação e cidadania em território fronteiriço: os brasiguaios na fronteira entre o Paraguai e o Brasil. Tomo, v. 1, n. 26, p. 97-122, 2015.

APPADURAI, Arjun. Modernity at large: cultural dimensions of globalization. Minneapolis: Universityof Minnesota Press, 1996.

ASSIS, Gláucia. Emigrantes brasileiros/as em mobilidade na virada do século XX para o século XXI - a diversificação de destinos. In: BÓGUS, Lucia; BAENINGER, Rosana (org.). A Nova face da emigração internacional no Brasil. São Paulo: Editora PUC, 2018, p. 235-264.

AVALLONE, Gennaro; SANTAMARÍA, Enrique (org.). Abdelmalek Sayad: uma lectura crítica. Migraciones, saberes y luchas. Madrid: Dado Ediciones, 2018.

BAENINGER, Rosana. Migrações transnacionais na fronteira: novos espaços da migração Sul-Sul. In: BAENINGER, Rosana; CANALES, Alejandro (orgs.). Migrações Fronteiriças. Campinas: Editora Unicamp, 2018, p. 462-474. 
BALIBAR, Étienne. Politics and the other scene. London: Verso, 2002.

BALIBAR, Étienne. We, the people of Europe? Reflections on transnational citizenship. United Kingdom: Princeton University Press, 2004.

BENEDETTI, Alejandro. Espacios fronterizos del sur sudamericano. Propuesta de un modelo conceptual para su estudio. Estudios Fronterizos, v. 15 n. 29, p. 1147, 2014.

BÓGUS, Lúcia. Brasileiros em Portugal: novos movimentos migratórios ou volta às origens? Travessia, v. VIII, n. 21, p. 16-19, 1995.

BOURDIEU, Pierre; SAYAD, Abdelmalek. El desarraigo: la violencia del capitalismo en una sociedad rural. Buenos Aires: SigloVeintiuno Editores, 2017.

BOYD, Monica. Family and personal networks in international migration: recent developments and new agendas. International Migration Review, v. 23, n. 3 p. 638-70, 1989.

CASTLES, Stephen; MILLER, Mark. The age of migration. London: Palgrave Macmillan, 2009.

CÔTÉ-BOUCHER, Karine. The diffuse border: Intelligence-sharing, control and confinement along Canada's Smart Border. Surveillance \& Society, v. 5, n. 2, p. 142-165, 2008.

CRESSWELL, Tim.On the move: mobility in the modern Western world. New York: Routledge Press, 2006.

CURRY, Michael. The profiler's question and the treacherous traveller: narratives of belonging in commercial aviation. Surveillance \& Society, v. 1, n. 4, p. 475499, 2004.

DALMASSO, Clara. Migración, terrorismo y seguridad: El migrante como amenaza terrorista en el discurso estatal argentino y en los discursos internacionales. (Dissertação de Mestrado) Facultad de Ciencia Política y Relaciones Internacionales, Universidad Católica de Córdoba, 2016.

DE CERTEAU, Michael. The practice of everyday life. Minnesota: University of Minnesota Press, 1997.

DE GENOVA, Nicholas. The legal production of Mexican/migrant 'illegality'. Latino Studies, v. 2, n. 2, p. 160-185, 2004.

DE GENOVA, Nicholas. Spectacles of migrant 'illegality': the scene of exclusion, the obscene of inclusion. Ethnic and Racial Studies, v. 36, n. 7, p. 1180-1198, 2013.

DE GENOVA, Nicholas. As políticas queer de migração: reflexões sobre “ilegalidade” e incorrigibilidade. REMHU, Revista Interdisciplinar da Mobilidade Humana, Brasília, v. 23, n. 45, p. 43-73, 2015.

DIAS, Gustavo. Brazilian migration into London: mobility and contemporary borders. (Tese de doutorado) Goldsmiths College/University of London, Department of Sociology, London, 2016.

DIAS, Gustavo. Fronteiras Britânicas: Políticas migratórias e a produção de experiências topofóbicas. In: BAENINGER, Rosana; CANALES, Alejandro (orgs.). Migrações Fronteiriças. Campinas: Editora Unicamp, 2018a, p. 115-130. 
DIAS, Gustavo. Onde estão as fronteiras? Como brasileiros indocumentados experienciam o regime de fronteiras britânicas. Travessia, v. 31, p. 99-120, 2018b.

DOMENECH, Eduardo. Inmigración, anarquismo y deportación: lacriminalización de los extranjeros "indeseables" en tiempos de las "grandes migraciones". REMHU, Revista Interdisciplinar da Mobilidade Humana, Brasília, v. 23, n. 45, p. 169-196, 2015.

DOMENECH, Eduardo. Las políticas de migración en Sudamérica:elementos para el análisis crítico del controlmigratorio y fronterizo.Terceiro Milênio: Revista Crítica de Sociologia e Política, v. 8, n. 1, p. 19-48, 2017.

FERREIRA, Suelda. Migração de Retorno - motivos e efeitos: final do ciclo migratório? In: SIQUEIRA, Sueli (org.). Ligações migratórias contemporâneas: Brasil, Estados Unidos e Portugal. Governador Valadares: Ed. Univale, 2018, p. 198-225.

GARELLI, Glenda. Migrants' struggles, practices of citizenship, and techniques of bordering. Border struggles, Londres, 17 de agosto de 2012.

HARVEY, David. Condition of postmodernity. Cambridge: Blackwell, 1989.

INGOLD, Tim. The perception of the environment: essays on livelihood, dwelling and skill. London: Routledge Press, 2000.

INGOLD, Tim. Against space: place, movement, knowledge. In: KIRBY, Peter (org.). Boundless worlds: an anthropological approach to movement. Oxford: Berghan Books, 2011, p. 29-45.

INGOLD, Tim. Being alive: essays on movement, knowledge and description. London: Routledge Press, 2011.

JARDIM, Denise. Imigrantes ou refugiados? As tecnologias de governamentalidade e o êxodo palestino rumo ao Brasil no século XX. Horizontes Antropológicos, v. 22, n. 46, p. 243-271, 2016.

KHOSRAVI, Shahram. The 'Illegal' traveller: an auto-ethnography of borders. London: Palgrave Macmillan, 2010.

KNOWLES, Caroline; HARPER, Douglas. Hong Kong: Migrant lives, landscapes, and journeys. Chicago: Chicago Press, 2009.

KNOWLES, Caroline. Cities on the move: navigating urban life. City, v. 15, n. 2, p. 136-153, 2011.

KNOWLES, Caroline. Nas trilhas de um chinelo: uma jornada pelas vias secundárias da globalização. São Paulo: Annablume Editora, 2017.

KUBAL, Agnieszka. Struggles against subjection: implications of criminalization of migration for migrants' everyday lives in Europe. Crime, Law and Social Change, v. 62, n. 2, p. 91-111, 2014.

LEFEBVRE, Henri. The production of space. Cornwall: T.J. Press, 1991.

MAGUIRE, MARK; FROIS, Catherine; ZURAWSKI, Nils (orgs.). The Anthropology of Security: Perspectives from the Frontline of Policing, Counter-terrorism and Border Control. London: PlutoPress, 2014.

MEZZADRA, Sandro; NEILSON, Brett. Border as method, or, the multiplication of labor. Durham: Duke University Press, 2013. 
MEZZADRA, Sandro. Multiplicação das fronteiras e das práticas de mobilidade. REMHU, Revista Interdisciplinar da Mobilidade Humana, Brasília, v. 23, n. 44, p. 11-30, 2015.

OLIVEIRA, Antonio Tadeu. Os invasores: as ameaças que representam as migrações subsaariana na Espanha e haitiana no Brasil. REMHU, Revista Interdisciplinar da Mobilidade Humana, Brasília, v. 23, n. 44, p. 135-155, 2015.

PAPADOPOULOS, Dimitris; STEPHENSON, Niamh; TSIANOS, Vassilis. Escape routes: control and subversion in the 21st century. London: Pluto Press, 2008.

PERERA, Suvendrini. Australia and the insular imagination: beaches, borders, boats, and bodies. New York: Palgrave Macmillan, 2009.

RIVERO SIERRA, Fulvio. Pensar el espacio, pensar los sujetos migrantes. Para una teoría de la apropiación subjetiva del espacio. Argumentos, v. 15, n. 1, p. 37-67, 2018.

ROCKEFELLER, Stuart. Flow. Current Anthropology, v. 52, n. 4, p. 557-578, 2011.

SALAZAR, Noel. Scapes. In: MCGEE, Jon; WARMS Richard (orgs.). Theory in social and cultural anthropology: An encyclopedia. Thousand Oaks: Sage, 2013, p. 205-234.

SEGA, Rodrigo. Canadá em quatro tempos: o fluxo migratório de brasileiros para Toronto. In: BÓGUS, Lucia; BAENINGER, Rosana (orgs.). A Nova face da emigração internacional no Brasil. São Paulo: Editora PUC, 2018, p. 205-234.

SCHROOTEN, Mieke; SALAZAR, Noel; DIAS, Gustavo. Living in mobility: trajectories of Brazilians in Belgium and the UK. Journal of Ethnic and Migration Studies, v. 42, n. 7, p. 1-17, 2015.

SHERINGHAM, Olivia. 'Thanks to London and to God': living religion transnationally among Brazilian migrants in London and 'back home' in Brazil (Tese de Doutorado) Queen Mary, University of London, 2011.

SOLÍS, Danil; AGUILAR, María del Carmen. Crisis del sistema migratorio y seguridad en las fronteras norte y sur de México. REMHU, Revista Interdisciplinar da Mobilidade Humana, Brasília, v. 23, n. 44, p. 83-98, 2015.

TUAN, Yi-Fu. Landscapes of fear. Minessota: University of Minnesota Press, 2013.

URRY, John. Sociology beyond societies: mobilities for the twenty-first century. London: Routledge, 2000.

URRY, John. Mobilities. Cambridge: Polity Press, 2007.

VILA, Pablo. Crossing borders, reinforcing borders: social categories, metaphors, and narratives identities on the U.S.-Mexico frontier. Austin: University of Texas Press, 2000.

VILLAMAR, María del Carmen; ALMEIDA, Gisele. Mobilidade humana: perspectivas e desafios - apresentação do dossiê. Terceiro Milênio: Revista Crítica de Sociologia e Política, v. 8, n. 1, p. 7-18, 2017. 